INTERNATIONAL JOURNAL
PHARMACEUTICAL SCIENCES
RESEARCH
REF

Received on 20 December, 2017; received in revised form, 20 February, 2018; accepted, 26 June, 2018; published 01 September, 2018

\title{
GREEN SYNTHESIS OF SILVER NANOPARTICLES USING LEAF EXTRACT OF AYAPANA TRIPLINERVIS AND ITS ANTIBACTERIAL ACTIVITY
}

Sona S. Dev *, K. U. Vineetha and Sneha Francis

Department of Biotechnology, St. Peter's College, Kolenchery, Kochi - 682311, Kerala, India.

\section{Keywords:}

Silver nanoparticles, Ayapana triplinervis, UV-Vis spectroscopy, FTIR, SEM

Correspondence to Author: Sona S. Dev

Assistant Professor, Department of Biotechnology, St. Peter's College, Kolenchery, Kochi - 682311, Kerala, India.

E-mail: sonaaniyan@gmail.com

\begin{abstract}
Green synthesis of nanoparticle using plant extracts is an efficient alternative for the conventional process of preparation of nanoparticles by chemical and physical methods which leads to non-ecofriendly by-products.The main aim of the project was to produce silver nanoparticles (AgNPs) using leaf extracts of Ayapana triplinervis (Eupatorium triplinerve) a medicinally important herb and to ascertain its antibacterial properties. AgNPs were synthesized by adding $1 \mathrm{ml}$ leaf extract of $A$. triplinervis to $10 \mathrm{ml}$ of $3 \mathrm{mM}$ silver nitrate followed by incubation at $60^{\circ} \mathrm{C}$. The AgNPs produced were further characterized by ultraviolet-visible (UV-Vis) spectroscopy, Fourier transform infrared (FT-IR) spectroscopy and scanning electron microscopy (SEM) analysis. UV-Vis spectroscopy of prepared silver colloidal solution showed absorption maximum between 460 - 490nm due to the excitation of surface plasmon resonance (SPR) of the AgNPs. FTIR spectra absorption peaks at 3431, 2065, 1635 and $530 \mathrm{~cm}^{-1}$ revealed the availability of functional groups which may be involved in the AgNPs synthesis. The SEM analysis showed that AgNPs were spherical or ellipsoidal in shape.The antibacterial activity against common pathogens was evaluated by well diffusion method. Salmonella, Pseudomonas and Bacillus gave positive results. The AgNPs produced in this study by green synthesis methodology from leaf extract of $A$. triplinervis needs to be further evaluated and could find greater application in pharmaceutical industry.
\end{abstract}

INTRODUCTION: Nanotechnology is science, engineering, and technology conducted at the nanoscale, which is about 1 to 100 nanometers. It is one of the most emerging branches of science and has wide applications when it combines with biotechnology. These emerge in the form of many lifesaving drugs and other medicines. There are various metals used for the synthesis of nanoparticles amongst which silver gained more attention due to its wide application.

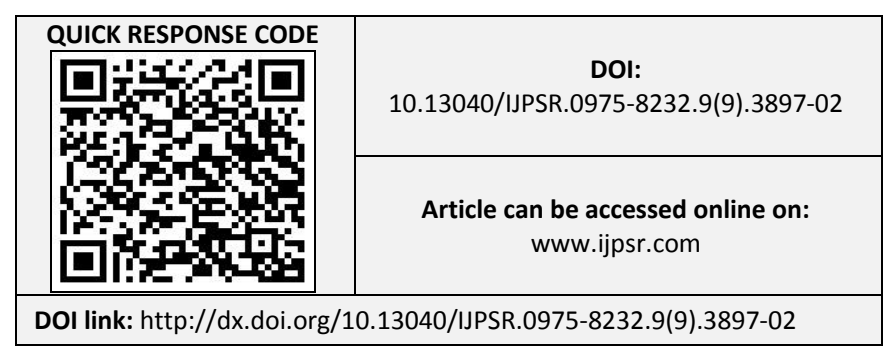

Silver nanoparticles have role in medicine, wound healing, packaging, textile, cosmetics, electronic, preservation, biolabelling etc ${ }^{1}$. Out of the several methods for the synthesis of silver nanoparticles, physical and chemical synthesis leads to the production of hazardous chemical and toxins that are harmful to the environment. These techniques are time consuming and not cost effective. Green synthesis of nanoparticle has thus gained the attention of scientists due to the cost effectiveness, eco-friendliness and easiness.

Green syntheses of AgNPs have been performed using plant extracts, microbial cell biomass or cell free growth medium and biopolymers. Over the past decade a variety of microorganisms such as bacteria $^{2}$, fungi ${ }^{3,4}$ have been used to synthesize AgNPs. 
Among the various biological methods of AgNPs synthesis, microbe-mediated synthesis is not feasible industrially as it requires maintenance of sterile conditions. The use of plant extracts for silver nanosynthesis in comparison to microbial systems is gaining momentum as it eliminates elaborate culture maintenance rituals followed by multiple purification steps ${ }^{5}$. Various plant parts like leaf, bark, root and stem have been used for the AgNP synthesis. Green synthesis using many medicinally important plants like Boerhaavia diffusa ${ }^{6}$, Tinospora cordifolia ${ }^{7}$, Terminalia chebula ${ }^{8}$, Catharanthus roseus ${ }^{9}$, Ocimum tenuiflorum ${ }^{10}$, Aristolochia indica ${ }^{11}$, Datura metel ${ }^{12}$, Calotropis gigantean $^{13}$, Cucurbita maxima ${ }^{14}$, Eucalyptus chapmaniana ${ }^{15}$ etc have been carried out by various scientists to explore their role in pharmaceutical industry .

The use of plants as the production assembly of silver nanoparticles has drawn attention, because of its rapid, eco-friendly, non-pathogenic, economical protocol and providing a single step technique for the biosynthetic processes ${ }^{16}$. The advantages of using plants for the synthesis of nanoparticles include their availability, safety in handling and presence of a variability of metabolites that may aid in reducing silver. One of the sources for the green synthesis of nanoparticle is the use of plant extract which acts as both reducing and stabilizing agent.

Phytochemicals are being used for health care since time immemorial, from remote areas to developed countries. Large quantities of phytochemicals are needed for the production of medicines and cosmetics. For the large scale production of these chemicals, mass production of plants are required. This will lead to the over exploitation of plant species and hence is a great challenge for the pharmaceutical industries. These problems can be solved through green synthesis of silver nanoparticle using plant extracts. These particles possess the effect of both silver and the plant extract. Thus the amount of plant extract needed can be reduced. Another reason for efficiency is the small size of nanoparticles.

Ayapana triplinervis (Vahl) (synonym: Eupatorium ayapana Vent; Eupatorium triplinerve Vahl) is a herbaceous, perennial aromatic herb belonging to Asteraceae family known for its medicinal value and its essential oil. The leaf juice and an infusion of the leaves and stems are considered as tonic, stimulant, astringent and antidysenteric. It is a rich source of naturally occurring coumarin chemicals. The essential oil extracted from leaf has antibacterial, antifungal and antihelmenthic property. So the main aim of the study was to produce silver nanoparticles using leaf extracts of A. triplinervis, to analyze its characteristics and study its antibacterial properties ${ }^{17}$.

\section{MATERIALS AND METHODS:}

Preparation of Leaf Extract: Ayapana triplinervis plants were collected from Elamkulam locality in Ernakulam district, Kerala Fig. 1 and deposited in the herbarium (voucher specimen no: SPC -1324). Fresh leaves of the plant were washed three times under running tap water and then in double distilled water to remove the impurities. It was then blot dried and cut into fine pieces. The leaf extract was prepared by adding $10 \mathrm{~g}$ leaves to $100 \mathrm{ml}$ distilled water and boiling at $100{ }^{\circ} \mathrm{C}$ for $10 \mathrm{~min}$. The mixture was allowed to cool to room temperature and filtered using Whatman no.1 filter paper.

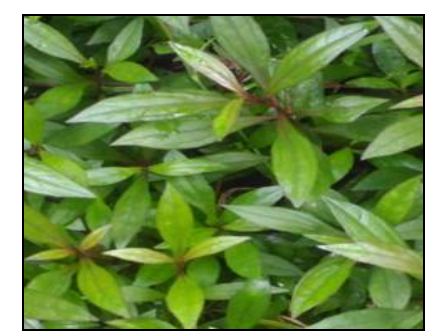

FIG. 1: AYAPANA TRIPLINERVIS PLANT IN ITS NATURAL HABITAT

Synthesis of Silver Nanoparticle: Silver nanoparticles (AgNPs) were prepared by adding $1 \mathrm{ml}$ of leaf extract to $10 \mathrm{ml}$ of $1 \mathrm{mM}, 3 \mathrm{mM}$ and $5 \mathrm{mM}$ $\mathrm{AgNO}_{3}$ respectively and incubated at $60{ }^{\circ} \mathrm{C}$ for $3 \mathrm{~h}$. This reaction was carried out in darkness to avoid photoactivation of $\mathrm{AgNO}_{3}$ solution. The colour change from light yellow to reddish brown colour indicated the presence of reduced $\mathrm{Ag}^{+}$. The solution was centrifuged at $12000 \mathrm{rpm}$ for $15 \mathrm{~min}$, followed by redispersion of the pellet in sterile double distilled water.

Characterization of Synthesised Silver Nanoparticles: The complete formation of silver nanoparticles was confirmed by measuring the absorbance spectra in 300-700nm range using UVVis spectrophotometer (Elico India). 
To determine the biomolecules present in the leaf extract, FTIR analysis was carried out using infrared spectral data collected on Thermo Avtar 370 FTIR spectrometer (CUSAT). The data was recorded in the spectral range of $4000-400 \mathrm{~cm}^{-1}$ resolution with an interferogram of 32 scans. SEM analysis was carried out for obtaining more structural information about the silver nanoparticles formed. The sample was smeared on a small piece of adhesive carbon tape which is fixed on a brass stub. The sample was then subjected to gold coating using sputtering unit (model: JFC1600) for $10 \mathrm{sec}$ at $10 \mathrm{~mA}$ of current. The gold coated sample was placed in chamber of SEM (Jeol, JSM 6390LA) and secondary electron/Back Scattered electron images are recorded.

Assessment of Antibacterial Activity: The antibacterial activity of the synthesized green silver nanoparticles against bacterial strains namely, Bacillus, E. coli, Salmonella, Staphylococcus, Klebsiella and Pseudomonas, was analysed by using well diffusion method ${ }^{18,19}$. Well diffusion method depends on the radial diffusion of an antibiotic from the well through semisolid agar layer in petri plate, which prevents the growth of bacteria in a circular area or the zone around the well. Luria Bertani broth (Himedia) was used as media for subculturing the microbes and incubated at $37{ }^{\circ} \mathrm{C}$ for $24 \mathrm{~h}$. A lawn of fresh culture was spread on the Muller Hinton agar (Himedia).

It was kept for two min to dry and then wells were made using a well cutter. Different concentrations of silver nanoparticles $(25 \mu \mathrm{g} / \mathrm{ml}, 50 \mu \mathrm{g} / \mathrm{ml}, 75 \mu \mathrm{g} / \mathrm{ml}$ and $100 \mu \mathrm{g} / \mathrm{ml}$ ) of AgNPs were added to the MHA agar plate. The treated plates were then incubated at $37{ }^{\circ} \mathrm{C}$ for $24 \mathrm{~h}$. The antibacterial action of AgNPs was evaluated by the extent of the zone of inhibition and their minimal inhibitory concentration. The experiment was repeated using the best found concentration of AgNPs producing maximum inhibition along with leaf extract alone, distilled water and silver nitrate as control.

\section{RESULTS AND DISCUSSION:}

Synthesis of AgNPs: When the aqueous extract of the leaf was added to $3 \mathrm{mM} \mathrm{AgNO}_{3}$ and kept at $60^{\circ} \mathrm{C}$, the reaction started in half an hour and the colour gradually deepened. The solution turned reddish brown and the reaction was completed in 3 h. Earlier researchers have also reported that the time required to reduce $90 \%$ of silver ions is approximately 2 to $4 \mathrm{~h}^{12}$. Silver disassembles into particles following the addition of plant extract, which may lead to a colour change. Solutions of AgNPs appear dark, yellow-brown in colour because of the surface plasmon resonance phenomenon ${ }^{20}$.

UV-Visible Spectra Analysis: UV-Vis spectroscopy refers to absorption spectroscopy in the UV-Vis spectral region. Light wave lengths in the 300-800 $\mathrm{nm}$ are generally used for characterizing various metal nanoparticles in the size range of $2-100 \mathrm{~nm}$ 21. UV-Vis spectroscopy is an important technique to determine the formation and stability of AgNPs in aqueous solution ${ }^{22}$. Spectrophotometric absorption measurement in the wavelength ranging from 400 to $450 \mathrm{~nm}$ is used to characterize AgNPs ${ }^{21,23}$.

The reduction of silver ions was primarily monitored by measuring the absorbance of the reaction mixture in a range of wavelength from 400 to $600 \mathrm{~nm}$ using UV-Vis spectrophotometer to find the absorbance peak. UV-Vis absorption spectrum showed characteristic peaks due to the surface plasmon resonance of AgNPs ${ }^{24}$.

Fig. 2 shows the UV-Vis spectra recorded after the completion of the reaction. There was an absorbance peak at $460 \mathrm{~nm}$ which indicated the presence of silver nanoparticles. Previous studies indicated that absorbance peaks around 400-480 $\mathrm{nm}$ are characteristic of AgNPs. The formation of AgNPs by reduction of $\mathrm{AgNO}_{3}$ using Withania somnifera root extract, macroalga Chaetomorpha linum extract and leaf extracts of Euphorbia prostrate ${ }^{25}$ have also produced resultant peak at 420nm when UV-visible spectroscopy was carried out.

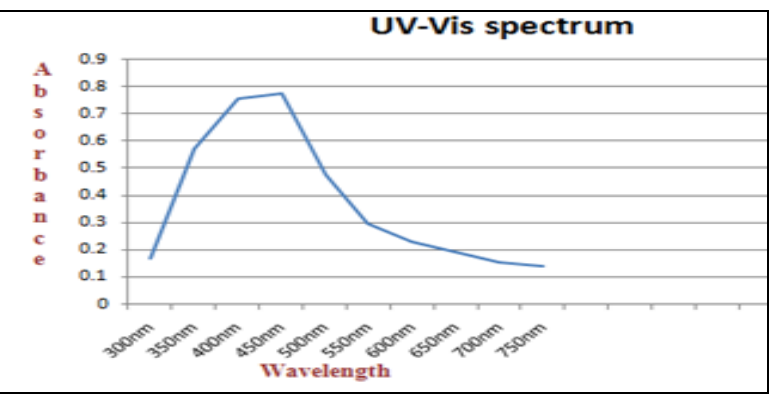

FIG. 2: UV-VIS SPECTRUM OF AgNPS SYNTHESIZED FROM LEAF EXTRACT OF A. TRIPLINERVIS 
FTIR Analysis: FT-IR is a molecular vibrational spectroscopy that dissects chemical functional groups in different absorbance regions between 4000 and $400 \mathrm{~cm}^{-1} 26$. FT-IR measurements are carried out to identify the possible biomolecules responsible for reduction, capping and efficient stabilization of AgNPs and the local molecular environment of the capping agents on the nanoparticle $^{27}$.

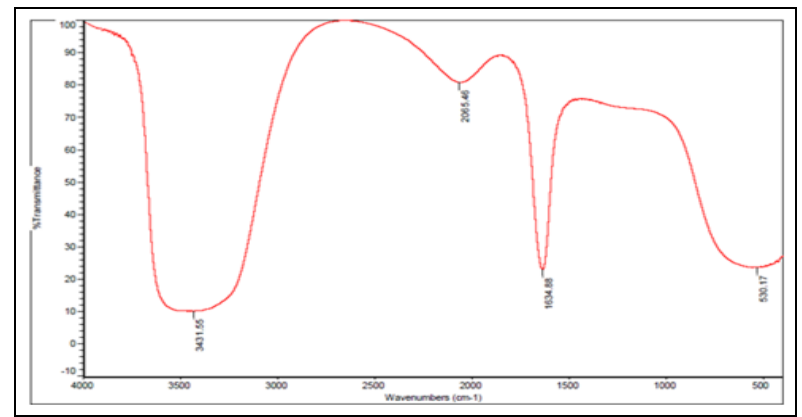

FIG. 3: FTIR SPECTRUM OF NANOPARTICLE SYNTHESISED FROM LEAF EXTRACT OF $A$. TRIPLINERVIS

FTIR spectroscopy analysis was accomplished to determine the functional groups responsible for the reduction of $\mathrm{Ag}+$ ions to $\mathrm{Ag}$ nanoparticles. FTIR is used to identify the biomolecules present on the surface of the nanoparticles which acts for capping and efficient stabilization of the metal nanoparticles 28. The FTIR spectra of the AgNPs obtained from leaf extract is shown in Fig. 3. The spectra showed many intense peaks between 3431 and $530 / \mathrm{cm}$, which reflect the diversity of biomolecules present in the extract. The FTIR spectrum of the silver nanoparticles obtained with the leaf extract showed peaks at 3431, 2065, 1635 and $530 \mathrm{~cm}^{-1}$. The spectral peak 3431.55 indicates the presence of $\mathrm{O}$ -
$\mathrm{H}$ stretch which denotes the presence of phenol group. The peak of 2065.46 represents the presence of aromatic compounds. The stretch 1634.88 indicates $\mathrm{C}=\mathrm{O}$ vibration which represents the carbonyl group attached to the protein groups. A similar range was reported by Fatimah (2016) and this confirms that reduction of silver had occurred 29. The peak of 530.17 indicates the $\mathrm{Ag}-\mathrm{O}$ stretch.The absence of FTIR bands between 2400 and $3300 / \mathrm{cm}$ confirms protein precipitation. FTIR results suggest that protein nanoparticle interaction occurs by free amine groups and electrostatic interaction of carboxyl groups. Earlier reports also state that proteins stabilize nanoparticles via precipitation thereby preventing agglomeration ${ }^{30}$.

SEM Analysis: SEM is a technique that uses electrons instead of light to form an output image ${ }^{31}$. The SEM analysis is employed to characterize the size, shape, morphology and distribution of synthesized AgNPs ${ }^{27}$. The SEM micrographs also indicate the purity and polydispersity of resulting $\mathrm{AgNPs}^{21}$.

The shape of the nanoparticles was ascertained using SEM. The images revealed the presence of a high density of well-dispersed silver nanoparticles which are spherical or ellipsoidal in shape. Fig. 4 shows representative SEM images recorded at different magnifications of the silver nanoparticles synthesized. Rajesh Kumar and Malarkodi (2017) found that $\mathrm{AgNp}$ synthesized from marine brown sea weed are highly agglomerated and form like cluster ${ }^{32}$. The particles were also found to be slightly agglomerated similar to that of nanoparticles synthesized from Acacia nilotica seeds ${ }^{33}$.
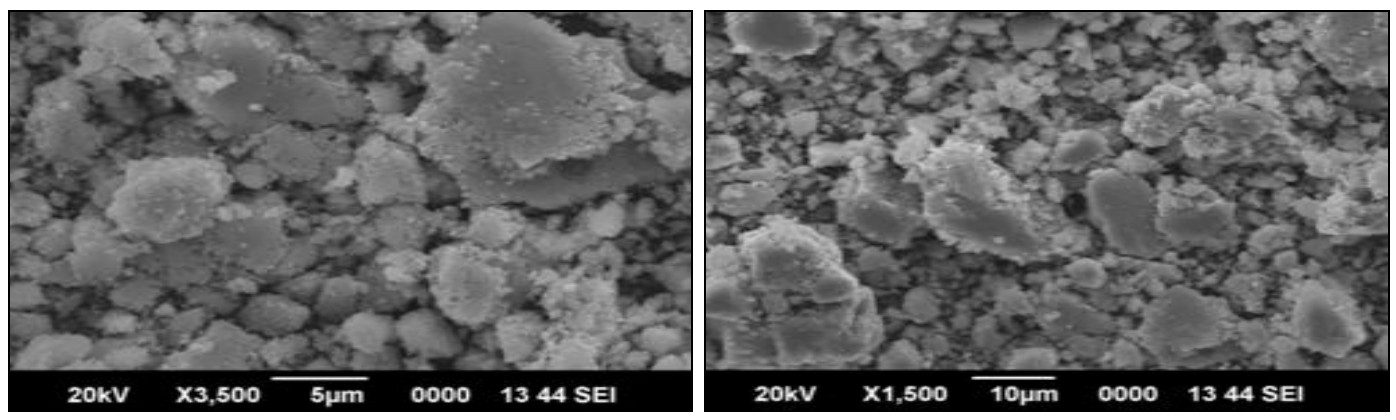

FIG. 4: SEM IMAGES OF NANOPARTICLES SYNTHESISED FROM AYAPANALEAF EXTRACT AT DIFFERENT MAGNIFICATIONS

Antibacterial Activity: The antibacterial activity of AgNPs produced were tested against bacteria such as E. coli, Bacillus, Klebsiella, Salmonella,
Staphylococcus and Pseudomonas by well diffusion method. It was observed that leaf extract alone has very less inhibition zone. 
The silver nanoparticle synthesised using leaf extract at $75 \mu \mathrm{g} / \mathrm{ml}$ showed the maximum antimicrobial effect on Salmonella $(7 \mathrm{~mm})$, Pseudomonas (9mm) and Bacillus (11 mm). It also showed slight resistance against Klebsiella and Staphylococcus. The threat posed by the potential outbreak of multidrug resistant bacteria is growing globally and demands the introduction and production of novel advanced platforms for the study and development of more potent antimicrobial agents. The diminishing efficacy and increasing toxicity of synthetic drugs further aggravate this problem. Scientists are hence directed to seek more natural or organic materials for solutions ${ }^{34}$. One potential source is the traditional medicine that has been practiced worldwide for centuries, for therapeutic purposes.

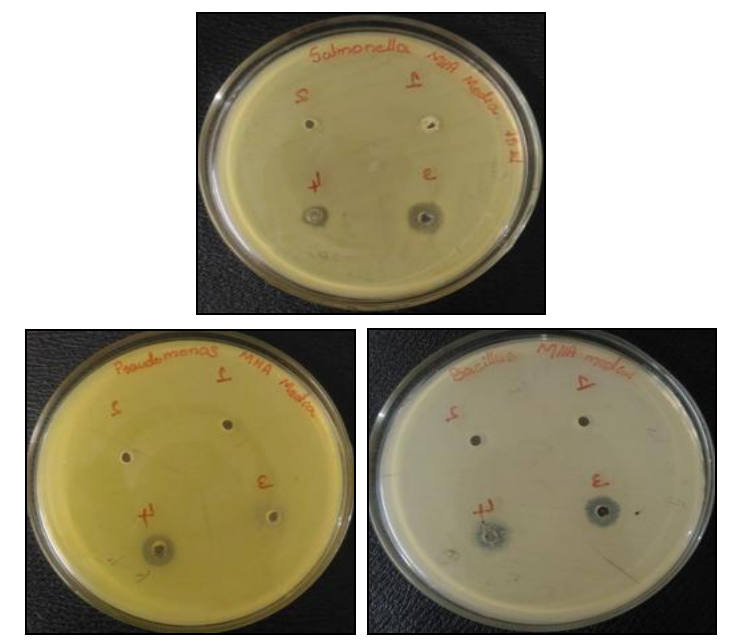

FIG. 5: ANTIMICROBIAL ACTIVITY OF SILVER NANOPARTICLE AGAINST SALMONELLA, PSEUDOMONAS AND BACILLUS 1) LEAF EXTRACT 2) DISTILLED WATER 3) SILVER NITRATE 4) LEAF NANOPARTICLE

AgNPs, which are filled with polyphenolic compounds, disrupt the cell walls of bacteria, which make gram-negative bacteria specifically sensitive. The antibacterial activity of Ag NPs is associated with several mechanisms including (i) generation of Reactive Oxygen Species (ROS) like super oxide anions and hydroxyl radicals (ii) the presence of $\mathrm{Ag}^{+}$ions in $\mathrm{Ag}$ NPs are making bond with sulphhydryl groups which direct to denaturation of proteins in the bacteria and (iii) release of $\mathrm{Ag}^{+}$ions from the Ag NPs which simply penetrate into the cell wall and cause severe damage to the bacteria and kill them. Moreover, nanosized AgNPs were attached to the bacteria and disturb the usual function of bacteria and hence damage severely the outer surface of the bacteria such as DNA, lipids and proteins ${ }^{35}$.

CONCLUSION: In this study, $A$. triplinervis conjugated Ag nanoparticles were synthesized using the leaf extract. The synthesized AgNPs were analyzed using UV-Vis spectrophotometer, FTIR and SEM. The rate of reduction has been observed to be moderately fast. The biosynthesized silver nanoparticles showed excellent antibacterial activity against Salmonella, Bacillus and Pseudomonas. The multidrug-resistant strains are a major problem in the control of infections in hospitals. The smaller size of nanoparticles is gaining importance in research for the treatment of various diseases. The main objective of this study was synthesis of silver nanoparticle in eco-friendly manner without using any hazardous chemicals. From the technological point of view these obtained silver nanoparticles have potential applications in the biomedical field and this simple procedure has several advantages such as costeffectiveness, compatibility for medical and pharmaceutical applications.

ACKNOWLEDGEMENT: We wish to thank the Kerala State Council for Science Technology and Environment, Kerala India, for the research funding.

CONFLICT OF INTEREST: Authors does not have any conflict of interest.

\section{REFERENCES:}

1. Roy S and Das TK: plant mediated green synthesis of silver nanoparticles - A review. Int J Plant Biol Res 2015; 3(3): 1044.

2. Kumar CG and Mamidyala SK: Extracellular synthesis of silver nanoparticles using culture supernatant of Pseudomonas aeruginosa. Colloids Surf., B Biointerfaces 2011; 84: 462466.

3. Singh, P and Raja RB: Biological synthesis and characterization of silver nanoparticles using the fungus Trichoderma harzianum. Asian. J. Exp. Biol. Sci 2011; 2 (4): 600-605.

4. Naveen HKS, Rao BKV, Kumar G and Karthik L: Extracellular biosynthesis of silver nanoparticles using the filamentous fungus Penicillium sp. Arch. Appl. Sci. Res 2010; 2(6): 161167.

5. Satyavani K, Gurudeeban $\mathrm{S}$, Ramanathan $\mathrm{T}$ and Balasubramanian $\mathrm{T}$ : Biomedical potential of silver nanoparticles synthesized from calli cells of Citrullus colocynthis (L.) Schrad. J. Nanotechnology 2011; 9: 43.

6. Vijaykumar PPN, Pammi SVN, Kollu P, Satyanarayana KVV and Shameem U: Green synthesis and characterization of silver nanoparticles using Boerhaavia 
diffusa plant extract and their antibacterial activity. Industrial Crops and Products 2014; 5: 562-566.

7. Anuj SA and Ishnava KB: Plant mediated synthesis of silver nanoparticles using dried stem powder of Tinospora cordifolia, its antibacterial activity and its comparison with antibiotics. International Journal of Pharmacy and Biological Sciences 2013; 4: 849-863.

8. Edison TJI and Sethuraman MG: Instant green synthesis of silver nanoparticles using Terminalia chebula fruit extract and evaluation of their catalytic activity on reduction of methylene blue. Process Biochemistry 2012; 47: 13511357.

9. Mukunthan KS, Elumalai EK, Patel EN and Murty VR: Catharanthus roseus: A natural source for synthesis of silver nanoparticles. Asian Pacific Journal of Tropical Biomedicine 2011; 1: 270-274.

10. Patil RS, Kokate MR and Kolekar SS: Bio-inspired synthesis of highly stabilized silver nanoparticles using Ocimum tenuiflorum leaf extract and their antibacterial activity. Spectrochimica Acta Part A: Molecular and Biomolecular Spectroscopy 2012; 91: 234-238.

11. Murugan K, Labeeba MA, Panneerselvam C and Dinesh D: Aristolochia indica green-synthesized silver nanoparticles: a sustainable control tool against the malaria vector Anopheles stephensi. R V S 2015; 102: 127-135.

12. Murugan K, Dinesh D, Kumar PJ and Panneerselvam C: Datura metel-synthesized silver nanoparticles magnify predation of dragonfly nymphs against the malaria vector Anopheles stephensi. Parasitol Res 2015; 114: 4645-4654.

13. Rajkuberan C, Sudha K, Sathishkumar G and Sivaramakrishnan S: Antibacterial and cytotoxic potential of silver nanoparticles synthesized using latex of Calotropis gigantea L. Spectrochim Acta A Mol Biomol Spectrosc 2015; 136: 924-930.

14. Nayak D, Pradhan S, Ashe S, Rauta PR and Nayak B: Biologically synthesized silver nanoparticles from three diverse family of plant extracts and their anticancer activity against epidermoid A431 carcinoma. J Colloid Interface Sci 2015; 457: 329-338.

15. Sulaiman GM, Mohammed WH, Marzoog TR, Al-Amiery AA, Kadhum AA, Mohamad AB and Bagnati R: Green synthesis, antimicrobial and cytotoxic effects of silver nanoparticles using Eucalyptus chapmaniana leaves extract. Asian Pac J Trop Biomed 2013; 3(1): 8-63.

16. Kulkarni $\mathrm{N}$ and Muddapur $\mathrm{U}$ : Biosynthesis of metal nanoparticles: a review. J Nanotechnol 2014; 1-8.

17. vanValkenburg JLCH and Bunyapraphatsara N: Plant Resources of South-East Asia 12: (2) Medicinal and Poisonous Plants. Backhuys Publishers, Leiden, the Netherlands 2001; 2: 91-93.

18. Sinah K, Panghal M, Kadyan S, Chaudary U and Yadav PJ: Antibacterial activity of synthesized silver nanoparticles from Tinospora cordifolia against multi drug resistant strains of Pseudomonas aeruginosa isolated from burn patients. J Nanomed Nanotechnol 2014; 5: 1-6.

19. Kanchana R and Pranjita Z: Plant- mediated synthesis of silver nanoparticles with diverse applications. Asian J Pharm Clin Res 2016; 9(1): 159-163.

20. Ankanna S, Prasada TNVKV, Elumalai EKB and Savithramma N: Production of biogenic silver nanoparticles using Boswellia ovalifoliolata stem bark. Dig J Nanomater Biostruct 2010; 5: 369-372.

21. Mittal AK, Chisti Y and Banerjee UC: Synthesis of metallic nanoparticles using plant extracts. Biotechnology Advances 2013; 31(2): 346-356.

22. Phillip D: Mangifera indica leaf-assisted biosynthesis of well dispersed silver nanoparticles. Spectrochim Acta Part A. 2011; 78(1): 327331. 72 .

23. Mittal AK, Bhaumik J, Kumar S and Banerjee UC: Biosynthesis of silver nanoparticles: elucidation of prospective mechanism and therapeutic potential. Journal of Colloid and Interface Science 2014; 415: 39-47.

24. Zhu H, Zhang C and Yin Y: Novel synthesis of copper nanoparticles: influence of the synthesis conditions on the particle size. Nanotechnology 2005; 16: 3070-3083.

25. Zahir AA, Bagavan A, Kamaraj C, Elango G and Rahuman AA: Efficacy of plant-mediated synthesized silver nanoparticles against Sitophilus oryzae. J Biopest. 2012; 5: 95-102.

26. Meng Y, Yao C, Xue S and Yang H: Application of Fourier Transform Infrared (FT-IR) spectroscopy in determination of microalgal compositions. Bioresource Technology 2014; 151: 347-354.

27. Chanda S: Silver nanoparticles (medicinal plants mediated): A new generation of antimicrobials to combat microbial pathogens- a review. In Méndez Vilas, A. (Ed). Microbial pathogens and strategies for combating them: Science, Technology and Education 2013; 1314-1323.

28. Padalia H, Moteriya $\mathrm{P}$ and Chanda S: Green synthesis of silver nanoparticles from marigold flower and its synergistic antimicrobial potential. AJC 2015; 8: 732-741.

29. Fatimah I: Green synthesis of silver nanoparticles using extract of Parkiaspeciosa Hassk pods assisted by microwave irradiation. Journal of Advanced Research 2016; 7 : 961-969.

30. Iravani S: Green synthesis of metal nanoparticles using plants. Green Chem 2011; 13(10): 2638-50.

31. Klein T, Buhr $\mathrm{E}$ and Frase GCF, Benakashania, Allafchianb AR and Jalali SAH: TSEM: A Review of scanning electron microscopy in transmission mode and its applications. Advances in Imaging and Electron Physics. 2012; 171: 297-356.

32. Kumar R and Malarkodi: Synthesis and characterization of silver nnoparticles from marine brown seaweed and its antifungal efficiency against clinical fungal pathogens. Asian J Pharm Clin Res 2017; 10(2): 0-193.

33. Prasad CH, Gangadhara S, Venkateswarlu S, Jyothi NV and Venkateswarlu P: Green synthesis of silver nanoparticles/microparticles using extract of Acacia nilotica seeds and their characterization. Int $\mathbf{J}$ Nanomat Biostruct 2014; 4(1): 1-4.

34. Benakashania F, Allafchianb AR and Jalali SAH: Biosynthesis of silver nanoparticles using Capparis spinosa L. leaf extract and their antibacterial activity. Karbala International Journal of Modern Science. 2016; 2(4): 251-258.

35. Gomathi M, Rajkumar PV, Prakasam A and Ravichandran K: Green synthesis of silver nanoparticles using Datura stramonium leaf extract and assessment of their antibacterial activity. Resource-Efficient Technologies. 2017; 3(3): 280-284.

How to cite this article:

Dev SS, Vineetha KU and Francis S: Green synthesis of silver nanoparticles using leaf extract of Ayapana triplinervis and its antibacterial activity. Int J Pharm Sci \& Res 2018; 9(9): 3897-02. doi: 10.13040/IJPSR.0975-8232.9(9).3897-02.

All @ 2013 are reserved by International Journal of Pharmaceutical Sciences and Research. This Journal licensed under a Creative Commons Attribution-NonCommercial-ShareAlike 3.0 Unported License.

This article can be downloaded to ANDROID OS based mobile. Scan QR Code using Code/Bar Scanner from your mobile. (Scanners are available on Google Playstore) 